\title{
Configuração epistemológica da Ciência da Informação na literatura periódica brasileira por meio de análise de citações (1972-2008)
}

Aline Elis Arboit

Mestranda em Ciência, Gestão e Tecnologia da Informação pela Universidade Federal do Paraná, Curitiba, Paraná, Brasil.

Leilah Santiago Bufrem
Doutora em Ciências da Comunicação pela Universidade de São Paulo. Pós-Doutora pela Universidad Autonoma de Madrid. Professora Titular do Departamento de Ciência e Gestão da Informação da Universidade Federal do Paraná, Curitiba, Paraná, Brasil.

Juliana Lazzarotto Freitas

Acadêmica do curso de Gestão da Informação, Universidade Federal do Paraná, Curitiba, Paraná, Brasil.

Analisa a configuração epistemológica da Ciência da Informação (CI) com base na análise de citações da produção periódica brasileira da área. Da Base de Dados Referenciais de Artigos de Periódicos de Ciência da Informação (BRAPCI) seleciona 91 artigos que versam sobre Epistemologia da CI. Identifica os autores mais produtivos e procede à análises de citações. Representa graficamente a incidência de citações dos autores constituintes da base BRAPCI e dos teóricos basilares da Epistemologia e da CI que influenciaram a temática na literatura periódica nacional.

Palavras-chave: Epistemologia; Ciência da Informação; Análise de Citações. 


\title{
Epistemic Configuration of Information Science in Brazilian Periodical Literature by Means of a Citation analysis (1972-2008)
}

\begin{abstract}
The article shows a study on the theoretical scenery related to epistemological questions of Information Science (IS) based on the theoretical context analysis of regular Brazilian production in this area. A total of 91 articles from the Reference Database of Information Science periodical articles (BRAPCI) were selected about the topic IS Epistemology. It identifies the ten most productive authors and proceeds with citation analysis; incidence of citations of the authors that compose the basis is graphically represented as well as the base theoreticians on epistemology that are more frequently cited in this corpus. It identifies the Brazilian most prominent authors in the theoretical context of IS, as well as the influences of the authors from the epistemological field on this area of literature in the period studied.
\end{abstract}

Keywords: Epistemology; Information Scienc, Citation Analysis.

Recebido em 13.10.2009 Aceito em 05.03.2010

\section{Introdução}

A epistemologia pode ser considerada o principal suporte de qualquer ciência, já que por meio dela se analisam seus fundamentos, seu vir a ser, suas relações entre teoria e prática. Para a Ciência da Informação (CI), os estudos sobre questões epistemológicas tornam-se fundamentais, pois diversamente das ciências convencionais como a Física ou a Química, ela é dotada de um alto grau de complexidade em função da sua recente consolidação e do seu multifacetado objeto de estudo: a informação.

Considerando-se que o desenvolvimento de uma ciência é refletido na produção científica, ou seja, que por meio das publicações a comunidade científica tem acesso a um novo conhecimento e o torna legítimo, o estudo da comunicação científica possibilita o exame e a avaliação dos conteúdos produzidos pelos cientistas, bem como as tendências, métodos e influências teóricas. Nesse contexto, desde o século XVII, o periódico científico figura como um dos mais importantes veículos de comunicação, pois proporciona disseminação, formalização, 
atualização com rapidez, ampliação e precisão dos conhecimentos científicos.

A análise de citações em artigos científicos tem sido uma técnica largamente utilizada para investigar o comportamento de produções científicas, tendências e influências de pensamento, avaliação de conteúdos, categorias, linhas e enfoques. Com essa compreensão, busca-se aqui descrever o estágio atual da configuração epistemológica da CI no Brasil via análise de citações da produção periódica nacional. O objetivo do trabalho consiste em responder a seguinte questão: como se configuram as questões epistemológicas no campo da CI no Brasil, segundo a análise de citações na literatura periódica da área?

O corpus da pesquisa é constituído pelos artigos registrados na Base de Dados Referenciais de Artigos de Periódicos de Ciência da Informação (BRAPCI), do qual foram selecionados 91 trabalhos que versam sobre o tema epistemologia da CI, no período entre 1972 e 2008 . Em seguida, foram levantados os teóricos constituintes da base BRAPCI e os teóricos fundamentais da área de epistemologia mais citados pelos autores mais produtivos da área. Deste modo, foi possível apontar os autores nacionais basilares da área da epistemologia da CI no Brasil e os autores do pensamento epistemológico mais influentes na área. Concebe-se, para este estudo, a CI em seu sentido mais amplo, relacionada com um domínio que abrange a origem, coleta, organização, armazenamento, recuperação, interpretação, transmissão, transformação e utilização da informação. Ao focar essa ciência, mais especificamente as revistas que a representam no Brasil, amplia-se a investigação para as representações da informação, o uso de códigos para uma eficiente transmissão de mensagens e o estudo dos serviços e técnicas de processamento da informação e seus sistemas de programação. Aceita-se o enfoque interdisciplinar com que tem sido tratada, dada sua relação com vários campos como a lógica, a lingüística, a psicologia, a informática, a estatística, as operações de pesquisa, as comunicações, a biblioteconomia, a gestão e outros campos limítrofes. Complementando, concebe-se a CI como uma ciência social dotada de um domínio teóricometodológico específico construído com a contribuição de outras disciplinas integrantes do mesmo núcleo como a arquivística, a biblioteconomia e a documentação e tangenciando as ciências sociais e humanas, como a história, a sociologia, a antropologia, a psicologia cognitiva e social e as ciências da educação. Seu campo de estudo abrange a gestão da informação, a produção, organização, representação e transferência da informação e o comportamento informacional.

\section{Epistemologia e Ciência da Informação}

O conceito de epistemologia constitui-se, por um lado, em categoria teórica históricamente constituída e, por outro, numa concepção filosófica aceita e analisada quando se realizam estudos críticos sobre as ciências. Embora o termo venha sendo utilizado para representar diferentes concepções, entre elas a de teoria do conhecimento e a de teoria da 
ciência, conforme sua etimologia grega, adota-se aqui a concepção de Lalande que o define como o "estudo crítico dos princípios, hipóteses e resultados das diversas ciências, destinado a determinar a sua origem lógica, o seu valor e a sua importância objetiva" (LALANDE, 1999, p. 313).

Se reconhecidos os desdobramentos históricos da evolução científica a partir do século XVIII (BLANCHÉ, 1972, p. 5), verifica-se que o termo ciência passa a adquirir um sentido mais estreito para representar conceitos relacionados ao processo e aos produtos decorrentes da prática científica, tais como academia de ciência, cultura científica, aplicações da ciência e todos os demais derivados dessa concepção. A partir de então, os termos ciência e conhecimento adquirem sentidos complementares, entretanto não idênticos, embora dicionaristas como Abbagnano tratem os termos epistemologia, teoria do conhecimento e gnoseologia como sinônimos. "Todos têm o mesmo significado" afirma o autor, para quem os termos não indicam uma disciplina filosófica geral, mas o "tratamento de um problema que nasce de um pressuposto filosófico específico, isto é, no âmbito de uma determinada diretriz filosófica" (ABBAGNANO, 1970, p. 160).

Ao definí-lo como estudo da ciência, destaca-se aqui uma orientação diferenciada, seguindo Lalande (1999, p. 314), segundo a qual a epistemologia é uma filosofia das ciências, pelo que se distingue da teoria do conhecimento, da qual serve, contudo, como introdução e auxiliar indispensável. A teoria do conhecimento, por sua vez, é o estudo que incide sobre a natureza, o processo e o alcance do conhecimento humano.

Adotando-se a distinção, procurou-se evidenciar na literatura periódica na área de CI, não apenas estudos sobre o tema epistemologia, mas aqueles orientados para questões concernentes à filosofia e natureza da CI, assim como suas relações mais evidentes com o conhecimento e a pesquisa. Ao se considerar a epistemologia da $\mathrm{CI}$, retoma-se a preocupação de Japiassu (1992), sobre a construção de uma epistemologia das ciências humanas e sua distinção entre os três tipos de epistemologia: a epistemologia global ou geral que trata do saber globalmente considerado, com a virtualidade e os problemas do conjunto de sua organização, quer sejam especulativos, quer científicos; a epistemologia particular que considera um campo particular do saber, quer seja especulativo, quer científico e a epistemologia específica que trata de levar em conta uma disciplina intelectualmente constituída em unidade bem definida do saber e de estudá-la de modo próximo, detalhado.

Embora este estudo seja voltado a um campo particular do saber e, portanto, se enquadre na categoria epistemologia particular, impõe-se considerar que as outras duas categorias estarão presentes quando da análise de conteúdo dos artigos participantes do corpus, especialmente pela característica da área de BCI, cujo domínio se constrói integrado aos saberes necessários a sua contrução científica.

Considerando-se que cabe à epistemologia refletir tanto sobre a teoria quanto sobre a prática das ciências, desde seu início, estruturação, 
formação e progresso, este estudo visa contribuir, assim, para a compreensão e consolidação do domínio científico.

Deve-se reconhecer, seguindo Gónzalez de Gómez, que a CI tem utilizado, desde sua origem, algumas dessas abordagens epistemológicas,

[...] apresentando-se ora como ciência empírico-analítica, ora como meta-ciência, ainda que nos últimos anos tenha explorado, achamos que com maiores perspectivas, um pluralismo metodológico próprio das ciências sociais e de um campo interdisciplinar (GONZÁLEZ DE GÓMEZ, 2001, p. 13).

Essa percepção é visível em estudos como os de Capurro (2003), sobre os três paradigmas da CI. O paradigma físico associado à área de Teoria Matemática da Informação de Shannon e Weaver, de 1972, cuja principal preocupação é a transmissão da informação, seria baseado na perspectiva epistemológica do Empirismo Lógico. Já o paradigma cognitivo, relacionado com as interações entre a informação e o sujeito individual, é influenciado pela Epistemologia Genética de Piaget e a Epistemologia de Popper ${ }^{1}$. Por sua vez, o paradigma social propõe a extensão dos estudos das interações entre a informação e o indivíduo para entre a informação e um contexto histórico e social. Aqui se observa a influência da teoria social do conhecimento ou sociologia do conhecimento.

Antes de Capurro (2003), Saracevic (1996) em seu trabalho "Ciência da informação: origem e evolução" faz uma abordagem evolutiva da CI. Evidencia que, com o passar do tempo, em função das mudanças de contexto histórico, os conceitos passavam a enfatizar as relações entre a informação antes voltada para o processo, depois para o indivíduo e, por último, para a sociedade.

Segundo Saracevic (1996), foi Borko, em 1968, o primeiro a conceituar $\mathrm{CI}$ :

$\mathrm{CI}$ é a disciplina que investiga as propriedades e 0 comportamento da informação, as forças que governam seu fluxo, e os meios de processá-la para otimizar sua acessibilidade e uso. A CI está ligada ao corpo de conhecimentos relativos à origem, coleta, organização, estocagem, recuperação, interpretação, transmissão, transformação e uso de informação... Ela tem tanto um componente de ciência pura, através da pesquisa dos fundamentos, sem atentar para sua aplicação quanto um componente de ciência aplicada, ao desenvolver produtos e serviços (BORKO, 1968 apud SARACEVIC, 1996, p. 45-46).

\footnotetext{
1 "De certa forma, a própria passagem das abordagens físicas para as cognitivistas sinaliza uma reação inicial que se manifesta com a criação de um "objeto mental". A informação-coisa é agora vista como uma imagem mental. Na literatura de campo, surgem inúmeras referências a Popper, com seu terceiro mundo de objetos inteligíveis (formulações lingüísticas compartilháveis, teorias, modelos e postulados de conhecimento sobre o mundo [...])" (CAMPOS; VENÂNCIO, 2007, p. 110).
} 
Em 1970, Goffman estabeleceu outro conceito mais específico para o campo. Embora a concepção de Goffman (1970 apud SARACEVIC, 1996, p. 46) coloque em pauta a questão dos princípios relacionados aos processos de comunicação e suas vertentes, ela é valorizada por Saracevic (1996), por sumariar fenômenos e processos que mereceriam ser analisados à época de sua formulação:

O objetivo da disciplina CI deve ser o de estabelecer um enfoque científico homogêneo para estudo dos vários fenômenos que cercam a noção de informação, sejam eles encontrados nos processos biológicos, na existência humana ou nas máquinas... Conseqüentemente, o assunto deve estar ligado ao estabelecimento de um conjunto de princípios fundamentais que direcionam o comportamento em todo processo de comunicação e seus sistemas de informação associados... (A tarefa da CI) é o estudo das propriedades dos processos de comunicação que devem ser traduzidos no desenho de um sistema de informação apropriado para uma dada situação física (GOFFMAN, 1970 apud SARACEVIC, 1996, p. 46).

Tomando a pesquisa de Saracevic (1996) como base, considera-se que as discussões da década de 1960 e inícios de 1970 sobre a CI foram representadas pelos conceitos expostos acima. Ao analisá-los, percebe-se que em ambos a preocupação central é a organização da informação voltada basicamente para suas propriedades, modos de comunicação e recuperação. Isto é, a ênfase é dada ao processo. Assim como no paradigma físico de Capurro (2003), aqui se verifica novamente a influência epistemológica do Empirismo Lógico.

Na primeira fase histórica da CI, a figura do usuário de informação, bem como a assimilação da informação por ele não é considerada como parte fundamental do processo. O sujeito começa a ser visto com mais importância, a partir da década de 70, com Kochen, em 1974, Belkin e Robertson (1976) e Becker (1976). Este período é marcado pela inserção dos estudos de ciências cognitivas na CI principalmente no que se refere aos processos mentais de assimilação, interpretação e uso da informação pelo indivíduo, conforme os conceitos abaixo:

Podemos conceitualizar o sistema de conhecimento, no qual se inscreve a recuperação de informação, como composto por três partes; (a) as pessoas em seu papel de processadores de informações; (b) os documentos em seu papel de suportes de informações; (c) os tópicos como representações. Estamos interessados no ciclo de vida de cada um destes três objetos e na dinâmica deinteração entre eles. Portanto, devemos considerar a variável comum aos três tempos (KOCHEN, 1974 apud SARACEVIC, 1996, p. 47).

Belkin e Robertson (1976 apud SARACEVIC, 1996, p. 47) defendem que "o propósito da CI é facilitar a comunicação de informações entre 
seres humanos", enquanto Becker (1976 apud SARACEVIC, 1996, p. 47) define a CI como o estudo do modo pelo qual as pessoas "criam, usam e comunicam informações". Observa-se, desse modo, que a epistemologia da CI acompanha a tendência das discussões epistemológicas sobre a ciência, pois o pensamento desta época, compatível com o chamado paradigma cognitivo por Capurro (2003), fundamenta-se nos projetos de Piaget e Popper.

Ainda de acordo com Saracevic (1996), a partir da década de 1980, devido ao relacionamento mais estreito da $\mathrm{CI}$ com a área de Administração, bem como, o desenvolvimento da tecnologia da informação, o eixo da CI passou a ser o contexto social da informação, ou seja, o uso da informação para a criação de conhecimento tanto individual como coletivo. A prática profissional da CI figura como a preocupação principal nessa fase. Em 1990, o próprio Saracevic elabora um novo conceito de CI como

[...] um campo dedicado às questões científicas e à prática profissional voltada para os problemas da efetiva comunicação do conhecimento e de seus registros entre os seres humanos, no contexto social, institucional ou individual do uso e das necessidades de informação. No tratamento destas questões são consideradas de particular interesse as vantagens das modernas tecnologias informacionais (SARACEVIC, 1996, p. 47).

Capurro e Saracevic conceituam a CI partindo da perspectiva de paradigmas, de acordo com $\mathrm{Kuhn}^{2}$, segundo a qual a CI teria surgido com um paradigma físico, questionado por um enfoque cognitivo. Este, por sua vez, substituído por um paradigma pragmático e social (CAPURRO, 2003). A crítica de Wersig (1993 apud CAMPOS; VENÂNCIO, 2007) de acordo com uma perspectiva realista, à visão paradigmática reside no fato de que poderia haver a promoção de uma competição entre eles, tratando-se de uma abordagem que não está direcionada a questões específicas e suas resoluções, interferindo no exercício transdisciplinar, em detrimento do enfoque multidisciplinar, que a área deveria colocar em prática. Segundo Campos e Venâncio (2007, p. 109), a CI deve ser evidenciada em seu "processo não-linear de fundação e reconfiguração".

Fundamentado nesse desenvolvimento não-linear da CI, Wersig (1993) propõe que ela seja vista não como uma ciência tradicional que tem um único objeto de estudo, mas sim como uma "nova ciência" ou uma ciência pós-moderna, que pode ter múltipos objetos, conceitos, interconceitos e métodos. O autor parte da crítica à necessidade de estabelecer um estudo baseado em paradigmas na CI nos moldes das ciências tradicionais, como tentativa de atestar sua cientificidade. Para

\footnotetext{
${ }^{2}$ Segundo Kuhn, o paradigma indica "toda constelação de crença, valores, técnicas partilhadas pelos membros de uma comunidade determinada" (KUHN, 2000 apud CAMPOS; VENÂNCIO, 2007, p. 108).
} 
sustentar tal proposta, fundamenta-se principalmente nas teorias de Feyerabend, Habermas e Luhmann.

Visto que na pós-modernidade a informação e o conhecimento são considerados como recursos essenciais para o desenvolvimento econômico e social, a CI figura, ao mesmo tempo, como fruto e como promessa de soluções para os problemas decorrentes dessa tendência. Pode-se inferir que a CI nasceu com e para a pós-modernidade reparar as conseqüências provocadas pela modernidade, como por exemplo, a explosão da informação ${ }^{3}$. Porém, a CI ainda mantém características das disciplinas científicas da modernidade.

Para Araújo (2003, p. 26) a CI "surge em um momento em que já se observavam as críticas e o início da crise que se abate sobre o modelo moderno da cientificidade". Entretanto, verifica que esta ciência, na tentativa de consolidação como domínio do saber, constrói-se tanto nos moldes da ciência moderna como na ciência pós-moderna (ARAÚJO, 2003). A incorporação da teoria matemática da informação, de Shannon e Weaver, as leis de Zipf, de Bradford, a Bibliotemetria, a Infometria, a Cientometria, exemplificam elementos teóricos que compõe a CI provenientes da ciência moderna.

Seguindo esta linha, Le Coadic (2003, p. 55) posiciona-se em prol de uma definição epistemológica da CI nos moldes da ciência moderna, apesar de compartir com a idéia de uma mudança nas condições do saber decorrente do ingresso das sociedades na chamada era pós-industrial e das culturas na chamada era pós-moderna. Para tanto, ele argumenta que a "CI identificou e delimitou seu objeto de estudo e problemas fundamentais de pesquisa: estudo das propriedades gerais (natureza, gênese e efeitos), dos processos e sistemas de construção, comunicação e uso da informação". Ou seja, segundo o autor, a CI conta com conceitos, métodos e leis científicos e técnicos considerados unívocos e que tendem à objetividade.

Por outro lado, retomando o pensamento de Wersig (1993), a CI possui outras características que permitem sua classificação como uma ciência pós-moderna. Assim como a pós-modernidade, a CI é marcada por uma falta de unidade teórica em muitos aspectos. A diversidade, a pluralidade e o indeterminismo, isto é, a incerteza acerca da suas origens, sobre seu objeto de estudo - a informação - e mesmo sobre seu conceito estão significativamente presentes no âmbito desta ciência. Este fato não poder ser atribuído somente aos poucos e recentes esforços de estudar mais a teoria da área, ou ao fato da CI ser uma nova ciência, mas também pela sua complexidade.

Além da complexidade, outra característica que reforçaria a tese de que a CI seja pós-moderna é a sua natureza interdisciplinar (ARAúJO, 2003). A CI busca nas outras áreas do saber não somente apropriação de conceitos, métodos, teorias e analogias, mas também a contribuição de

\footnotetext{
3 "[...] crescimento exponencial na produção de conhecimento/informação e o avanço desmesurado das possibilidades tecnológicas para seu registro, circulação e divulgação" (CARDOSO, 1996, p. 73).
} 
novos conhecimentos em uma relação de troca, reciprocidade e aproveitamento mútuos.

As características epistemológicas da CI podem ser levantadas por meio da análise da literatura, sobretudo a periódica, que por sua vez é considerada mais importante na área. Sendo assim, julgou-se necessário verificar como se configura epistemologicamente esta ciência via análise de citações, e conseqüentemente, de influências teóricas dos artigos científicos da área que versam sobre o tema Epistemologia da CI.

\section{Produção científica na literatura periódica brasileira em CI}

Os periódicos científicos são, por excelência, os meios mais eficazes de comunicação científica, desde o século XVII. De acordo com Meadows (1999), o motivo principal pelo qual surgiram os periódicos encontra-se na necessidade de comunicação, do debate coletivo de forma eficiente procurando a partir disto a realização de novos descobrimentos. Desde então, o crescimento da produção periódica acompanhou a expansão da ciência e da comunidade científica e, também, passou a ser fundamental para atualização deste público.

Diante disso, os periódicos representam grande parte da consolidação do conhecimento desenvolvido por uma ciência. Portanto, ao estudar a consolidação de qualquer ciência como domínio do conhecimento, não se pode desconsiderar a relevante contribuição registrada nos periódicos científicos. De acordo com Tenopir e King (2001, p. 23),

a informação contida nos periódicos se presta a muitas finalidades (pesquisa, ensino, serviços de alerta, leitura básica, etc.) para os cientistas, tanto no contexto universitário quanto no não universitário [...] eles relatam que os artigos são de grande importância para seu trabalho, mais do que qualquer recurso informacional (TENOPIR; KING, 2001, p. 23).

Sendo assim, considera-se que o estudo diacrônico da produção em revistas científicas oferece perspectivas para compreender a história da construção intelectual de áreas do conhecimento específicas, possibilitando a reflexão sobre tendências da literatura científica e influências teóricas (BUFREM, 2006, p. 194).

Os primeiros periódicos científicos brasileiros da área de CI surgiram somente na década de 1970. "Em 1972, foram criados a Ciência da Informação, sob a responsabilidade do IBICT, e a Revista da Escola de Biblioteconomia da UFMG, que teve seu título alterado em 1996 para Perspectivas em Ciência da Informação, editada pela Escola de Ciência da Informação da UFMG" (ANDRADE; OLIVEIRA, 2005, p. 52) ${ }^{4}$. No ano

\footnotetext{
${ }^{4}$ Enquanto no Brasil a $\mathrm{Cl}$ dava seus primeiros passos, no mundo ela já havia evoluído, já tinha mudado seu eixo do processo de organização e recuperação da informação para, além o processo, a assimilação da informação pelo usuário. Diante disto, adota-se aqui a hipótese de que nos anos 1970 a "Cl brasileira" ainda estava preocupada somente com o processo.
} 
seguinte, foi criada a Revista Brasileira de Biblioteconomia e Documentação, pela Federação Brasileira de Associações de Bibliotecários (FEBAB). Somente em 1989, o Mestrado de Biblioteconomia da PUCCampinas passou a editar a próxima revista da área: a Transinformação. Em 1991, o Mestrado em Biblioteconomia da Universidade Federal da Paraíba criou o título Informação \& Sociedade: Estudos e, no final desta década, passa a ser publicada via Internet pelo Instituto de Adaptação e Inserção na Sociedade da Informação (IASI) a revista Datagramazero. Depois, outras publicações essencialmente eletrônicas surgiram: a Encontros Bibli: revista de Biblioteconomia e Ciência da Informação, do Mestrado em Ciência da Informação da Universidade Federal de Santa Catarina, em 2002; a Revista Biblos, do Departamento de Biblioteconomia e História, da Fundação Universidade do Rio Grande; e recentemente a Revista Digital de Biblioteconomia e Ciência da Informação, do Sistema de Bibliotecas da UNICAMP (BUFREM, 2006, p. 200).

A produção de revistas científicas no Brasil - especialmente em áreas as quais a consolidação científica ainda se encontra em construção, como a CI - refletem as dificuldades devido a problemas de estabilidade política e financeira enfrentas pelo país. Além disso,

[...] a Ciência da Informação conta com uma infra-estrutura, ainda incipiente, de ensino e pesquisa, uma vez que seu apoio institucional está em fase de implantação. Para o desenvolvimento das atividades científicas, torna-se necessária uma infra-estrutura mínima composta por elementos básicos, a saber: instituições de ensino e pesquisa fortes, bem como apoio às atividades de pesquisa, recursos humanos qualificados e canais de comunicação e intercâmbio científico (ANDRADE; OLIVEIRA, 2005, p. 46).

\section{Metodologia e resultados}

O corpus da pesquisa é constituído pelos artigos de periódicos registrados na base Brapci. Essa base de dados é o produto de informação do projeto de pesquisa "Opções metodológicas em pesquisa: a contribuição da área da informação para a produção de saberes no ensino superior", cujo objetivo é subsidiar estudos e propostas na área de Ciência da Informação e que se fundamenta em atividades planejadas institucionalmente. Com esse propósito, foram identificados os títulos de periódicos da área de CI e indexados seus artigos, constituindo-se a base de dados referenciais.

Uma análise preliminar da BRAPCI permitiu a identificação e recorte de 95 artigos publicados entre 1972 e 2008 que versam sobre questões epistemológicas, entre os quais 91 relacionavam-se especificamente ao campo da CI no Brasil, conforme lista em anexo. Os descritores de busca utilizados na recuperação dos artigos na BRAPCI foram: epistemologia; teoria do conhecimento; teoria da ciência; teoria da CI; história da 
ciência; ciência da ciência; filosofia da ciência, gnosiologia e epistemológico(a).

A análise dos 91 artigos, selecionados a partir do recorte da BRAPCI, possibilitou o levantamento dos pesquisadores mais produtivos sobre Epistemologia na CI nos periódicos nacionais. Foram selecionados somente os autores que publicaram de três artigos ou mais dentro do recorte. Esse primeiro resultado está representado no Gráfico 1 que, além de identificar os autores mais produtivos, traz, respectivamente, a quantidade de artigos elaborados por cada um.

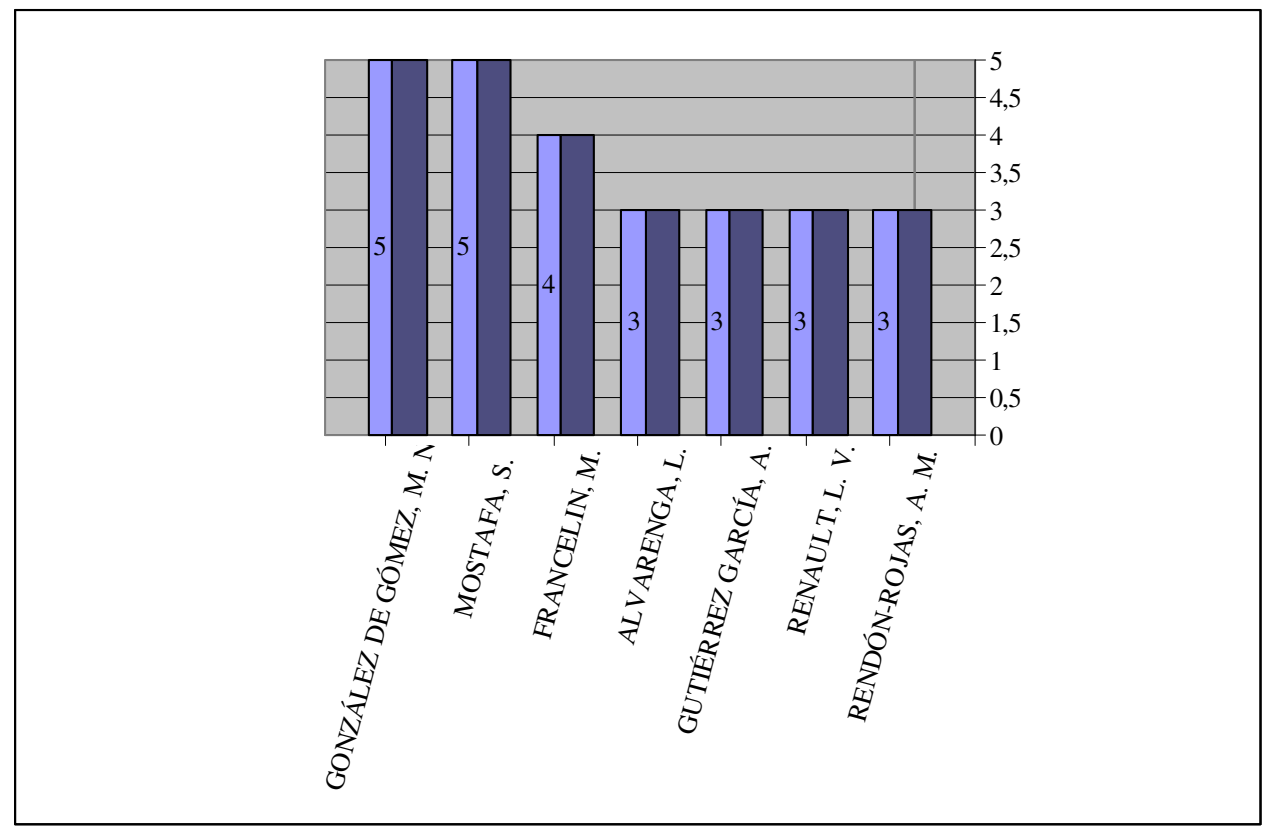

GRÁFICO 1 - Autores mais produtivos sobre Epistemologia na CI nos periódicos nacionais

Fonte: Pesquisa na base BRAPCI (2008).

No GRÁF. 1, nota-se que Maria Nélida González de Gómez e Solange Mostafa destacaram-se com artigos sobre o tema epistemologia da CI, ambas com seis artigos do total da produção analisada, seguidas de Marivalde Francelin, com quatro e de Lídia Alvarenga, Antônio Garcia Gutiérrez, Leonardo Vasconcelos Renault e Angel Miguel Réndon Rojas, com três incidências.

Com base no recorte ilustrado pelo GRÁF. 1, procedeu-se à análise de citação dos artigos de autoria dos pesquisadores representados. A análise de citação foi realizada em duas etapas: 1) foram identificados os dez autores registrados na base BRAPCI mais citados pelos autores que mais publicaram artigos sobre o assunto; 2) foram identificados, com até dez incidências, os teóricos relacionados ao campo da Epistemologia e da CI mais citados pelos autores mais produtivos. Dessa forma, foi possível descobrir os autores basilares na área epistemológica da CI no Brasil e os teóricos do campo epistemológico que tem mais impacto na área. 


\section{Análise e discussão dos resultados}

Os resultados da análise de citações apresentados no GRÁF. 2 apontam Maria Nélida González de Gómez (com 27 citações) como principal autora de Epistemologia da CI no Brasil, destacando-se entre seus títulos "A informação como instância de integração de conhecimentos, meios e linguagens: questões epistemológicas, conseqüências políticas", "Da organização do conhecimento às políticas de informação", "Metodologia de pesquisa no campo da Ciência da Informação", "O contrato social da pesquisa: em busca de uma nova equação entre a autonomia epistêmica e autonomia política", de 2006; "A vinculação dos conhecimentos: entre a razão mediada e a razão leve", de 2005; "Novas fronteiras tecnológicas das ações de informação: questões e abordagens", de 2004; "As relações entre ciência, Estado e sociedade: um domínio de visibilidade para as questões da informação", de 2003; "Dos estudos sociais da informação aos estudos do social desde o ponto de vista da informação", 2002; "O caráter seletivo das ações de informação", "Metodologia da pesquisa no campo da Ciência da Informação", de 2000; "Da organização do conhecimento às políticas de informação", de 1996; "A informação: dos estoques às redes", de 1995; "Da representação do conhecimento ao conhecimento da representação", de 1993; "O objeto de estudo da Ciência da Informação: paradoxos e desafios", de 1990; "O papel do conhecimento e da informação nas formações políticas ocidentais", de 1987; "A configuração temática de ciência da informação no currículo dos cursos do IBICT: estudo do caso", de 1982.

Em seguida, com 19 citações aparecem Emília Currás e Antonio García Gutiérrez. Entre nove e seis citações verificam-se os nomes de Solange Mostafa, Rosaly Favero Krzyzanowski, Aldo Barreto, M. C. Cavalcanti, Maria Lopez Ginez de Lara, Lena Vânia Pinheiro e Rubens Ribeiro Gonçalves da Silva. 


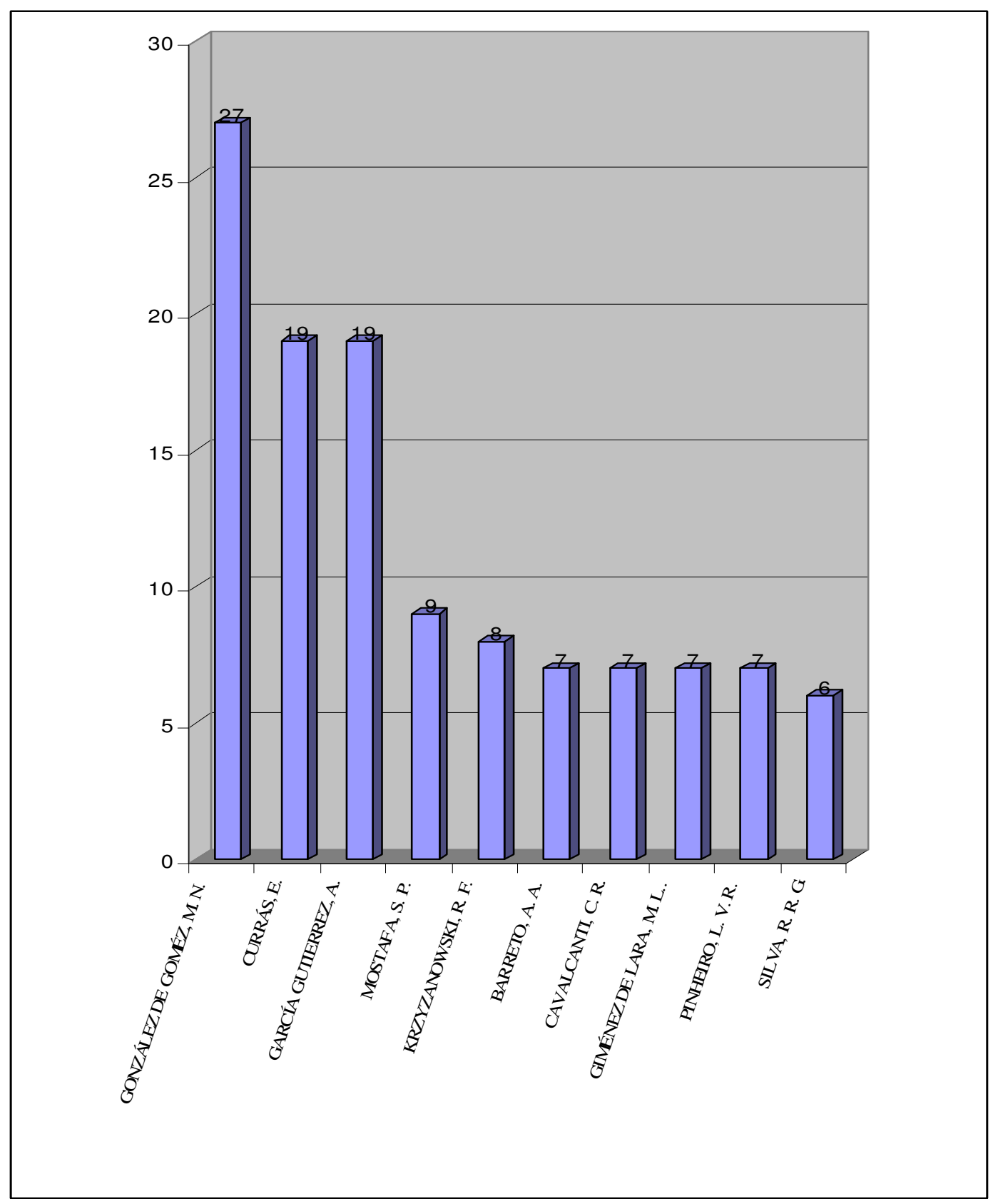

GRÁFICO 2 - Autores constituintes da base BRAPCI mais citados da produção sobre questões epistemológicas na literatura periódica da área de CI

Fonte: Pesquisa na base BRAPCI (2008).

Em relação ao GRÁF. 3, verifica-se ainda a incidência de autores oriundos de basicamente três áreas do conhecimento. Da CI, destacam-se Capurro, Wersig, Saracevic, Shera, Mikhailov, Brookes, Belkin, Buckland e Shannon; enquanto a filosofia da ciência é representada por Morin, Latour, Kuhn, Focault, Boaventura Santos, Japiassu, Frohmann, Lakatos, Popper, Bachelard, Prigogine, Feyerabend, Moles e Habermas, e a sociologia, por Castells. 

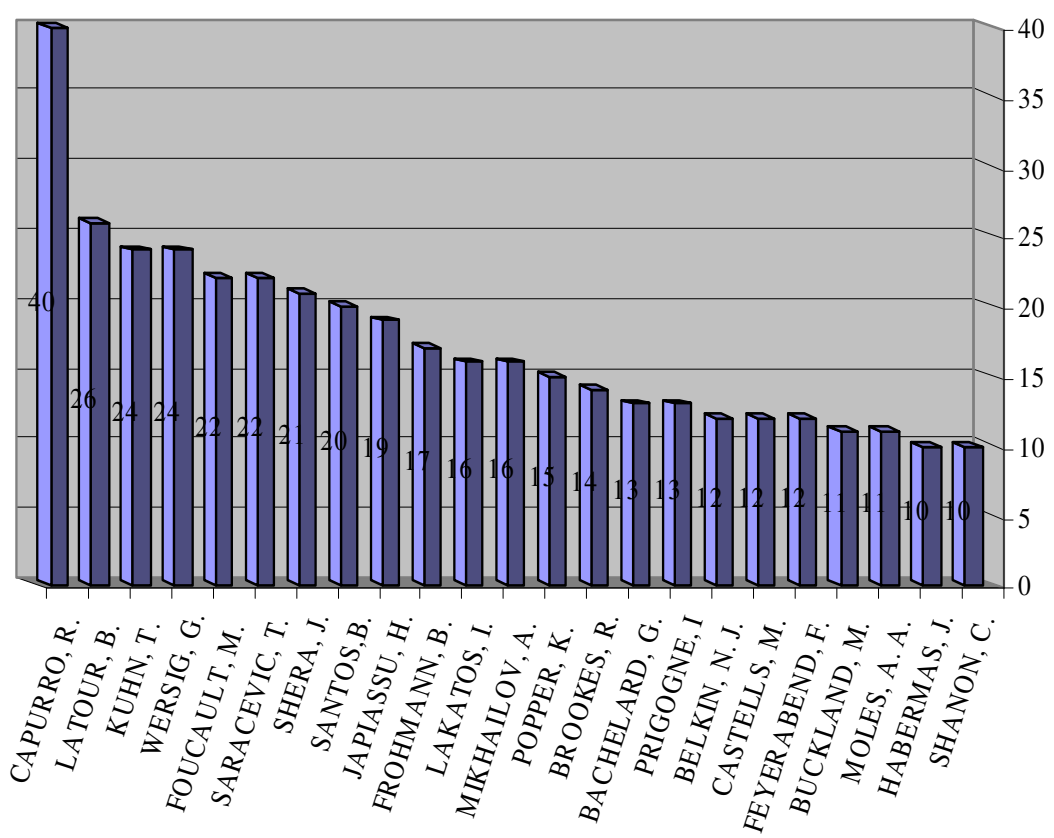

GRÁFICO 3 - Teóricos da área de epistemologia mais citados pelos autores mais produtivos sobre questões epistemológicas na literatura periódica da área de CI.

Fonte: Pesquisa na base BRAPCI (2008).

Destaca-se Morin como o mais citado dos autores "fundantes" (42 registros), de modo especial por seus estudos sobre a complexidade, característica determinante da crise de modernidade, principalmente no âmbito científico. Para Morin, a complexidade surge como dificuldade, como incerteza e não como clareza e como resposta, problematizando sobre a possibilidade de responder ao desafio da incerteza e da dificuldade. $O$ autor tem expressiva presença na literatura sobre a transdisciplinaridade, considerada como alternativa para o desenvolvimento da ciência, em detrimento de uma visão essencialmente positivista e suas obras representativas nesse corpus foram: "Introdução ao pensamento complexo" (1990); "O paradigma perdido: a natureza humana" (1991); "As grandes questões do nosso tempo" (1994); "O problema epistemológico da complexidade" (1996); "O método 3: o conhecimento do conhecimento" (1999); "Por uma reforma do pensamento" (1999); "A inteligência da complexidade" (2000); "A cabeça bem feita: repensar a reforma, reformar o pensamento" (2002); " $A$ ciência com consciência" (2002) e "O método 1: a natureza da natureza" (2002).

Distinguido com 40 citações, Capurro enfoca o tema Epistemologia da Ciência da Informação adotando uma visão paradigmática, fundamentada em Kuhn e sustentando sua teoria sobre o desenvolvimento da CI em três paradigmas: físico, cognitivo e social, de 
modo a compor teoricamente o que passou a ser conhecido como o Trilema de Capurro. Destacam-se seus títulos "Epistemologia e Ciência da Informação" (2003), "Angeletics: a message theory" (2003), "Foundations of information science: review and perspectives" (2003); "Heidegger y la experiencia del lenguaje" (1982), "Hermeneutics and the phenomenon of information" (2000), "What is Information Science for? A Philosofical Reflection" (1992), "Is a unified theory of information feasible? $A$ trialogue" (2004) e "The concept of information" (2006).

Representados numa segunda faixa, entre 24 e 19 citações, aparecem Latour, com seu título "Ciência em ação" (2000); Kuhn e sua obra principal "As estruturas das revoluções científicas"; Wersig, com o polêmico artigo "Information science: the study of postmodern knowledge usage"; Foucault, com principalmente "A arqueologia do saber"; Saracevic, com "Ciência da Informação: origem, evolução e relações", de 1996; Shera, com o artigo de 1976, "Toward a theory of librarianship and information science"; Boaventura Santos, com "Introdução a uma ciência pós-moderna" (2000), "Um discurso sobre as ciências", (2002), "A crítica da razão indolente" (2001); e Japiassu, com destaque para as obras "Introdução ao pensamento epistemológico" (1970) e "Interdisciplinaridade e patologia do saber" (1986).

Situados em uma terceira faixa (entre 17 e 10 citações) aparecem Frohmann, Imre Lakatos, Mikhailov, Popper, Brookes, Bachelard, Prigogine, Belkin, Castells, Feyerabend, Buckland, Moles, Habermas e Shannon, representando posições diversas, embora em certos casos relacionadas. É o caso de Lakatos, que valorizou o pensamento popperiano como o desenvolvimento filosófico mais importante do século $\mathrm{XX}$, sem deixar de considerar as críticas que recebeu de Kuhn e Feyerabend.

A atribuição dada a CI como uma ciência marcada pela complexidade, pela interdisciplinaridade e, mais recentemente, pela transdisciplinaridade é sustentada pela significativa incidência de autores como Morin, Japiassu, Saracevic, Krzyzanowski e Pinheiro.

Nos dois gráficos (GRÁF. 2 e 3), verifica-se a forte presença de autores que abordam a temática da pós-modernidade e defendem a CI como uma ciência pós-moderna. Dentre esses, destaca-se Wersig. O aparecimento de autores como Boaventura Santos, Foucault, Prigogine, Feyerabend e Castells reforça essa tendência.

No entanto, vale ressaltar que essa concepção não é unânime na área, pois ainda há influência dos autores que estudam a CI nos moldes da ciência moderna como Buckland, Shannon e Mikhailov, principalmente. A freqüência de autores cujos estudos descartam a idéia de pósmodernidade como Latour e Habermas sugere a presença de uma crítica à concepção pós-moderna da CI. Neste sentido, em contraposição ao pensamento pós-moderno também se observa, ainda, a influência significativa da visão paradigmática, representada principalmente por Capurro, Saracevic e Kuhn. 
Há que se considerar as concepções de autores como González de Gómez, Currás, García Gutierrez, Mostafa, Krzyzanowski, Barreto, Frohmann, Shera, Latour, Habermas, Bachelard, Castells e Moles como decorrentes de vertentes que privilegiam os aspectos social, histórico e político da CI. Por sua vez, as posições de Belkin, Popper, Lakatos, Brookes, Cavalcanti e Gimenez de Lara privilegiam os aspectos cognitivo e lingüístico.

\section{Considerações finais}

A análise de citações da literatura periódica representa uma complexa rede de relações temáticas presente nas reflexões sobre aspectos epistemológicos relacionados à $\mathrm{CI}$, já antes revelada mediante $\mathrm{o}$ estudo teórico. Por meio do estudo empírico, foi possível estabelecer uma configuração representativa do estado das questões epistemológicas no âmbito da CI. As principais características levantadas foram a diversidade de linhas de pensamento, o predomínio de abordagens de cunho social em detrimento de abordagens exatas e cognitivas e a ênfase dada a temas como complexidade, inter e transdicisplinaridade, pós-modernidade e paradigmas.

A diversidade de linhas de pensamento adotadas pelos autores levantados demonstra intenso pluralismo presente no campo teórico da CI. No entanto, observa-se o predomínio de abordagens de cunho social, histórico e político que tratam a CI como uma ciência social, principalmente no GRÁF. 2, representadas pelos autores González de Gómez, Currás, García Gutierrez, Mostafa, Krzyzanowski e Barreto, e no GRÁF. 3, por Frohmann, Shera, Latour, Habermas, Bachelard, Castells e Moles. Também se destaca a influência significativa dos teóricos considerados pós-modernos, como Boaventura Santos, Wersig, Foucault, Prigogine, Feyerabend e Castells. O aparecimento de autores que ressaltam temas como a complexidade, a inter e transdisciplinaridade da CI, como Morin, Japiassu, Saracevic, Krzyzanowski e Pinheiro reforçam a preponderância do pensamento pós-moderno. Este, não somente leva em consideração essas temáticas, mas defende que a temática relacionada à complexidade, à inter e à transdisciplinaridade são algumas das principais características do movimento.

Porém, a incidência de autores, mesmo que pouco expressiva, como Habermas e Latour, mostra que a área não se encontra imune às críticas ao movimento pós-moderno, além, da presença de Buckland, Shannon e Mikhailov que, por sua vez, tratam a CI como ciência exata e Belkin, Popper, Lakatos, Brookes, Cavalcanti e Lara que, privilegiando os aspectos cognitivo e lingüístico, permitem que se reflita sobre a CI como uma ciência humana. E ainda, há considerável parcela de trabalhos que têm uma visão paradigmática da CI como os de Capurro, Saracevic e Kuhn.

Além da diversidade de pensamento, outro ponto a ser notado é a presença, ainda que com diferentes intensidades, das abordagens social, cognitiva e exata, sugerindo a insustentável posição de uma visão 
essencialmente paradigmática. Em outras palavras, retoma-se 0 pensamento de Wersig (1993) contra a concorrência entre as três abordagens.

Também vale ressaltar que o debate epistemológico nacional da CI acompanhou as tendências de debate do campo epistemológico, o que se confirma pela influência de autores provenientes dos campos filosóficos e sociológicos, detectada pela incidência de citações. Pode-se observar ainda a marcante influência de autores estrangeiros de todos os campos, sendo Hilton Japiassu o único teórico brasileiro que aparece no GRÁF. 2.

Apesar de acompanhar os debates epistemológicos, a presença de somente 91 artigos em um universo de quase 5.000 mostra que os estudos nesta área ainda podem ser considerados incipientes, em decorrência da intensa flutuação e multiplicidade de pensamento indicativa de uma ciência cujas questões mais prementes apresentam-se como estágio preliminar de discussões epistemológicas mais intensas no contexto da CI no Brasil.

\section{Referências}

ABBAGNANO, N. Dicionário de filosofia. São Paulo: Mestre Jou, 1970.

ANDRADE, M. E. A.; OLIVEIRA, M. A ciência da informação no Brasil. In: OLIVEIRA, M. Ciência da informação e biblioteconomia: novos conteúdos e espaços de atuação. Belo Horizonte: UFMG, 2005. p. 45-56.

ARAúJO, C. A. A. A ciência da informação como ciência social. Ciência da Informação, Brasília v. 32, n. 3, p. 21-27, 2003.

BECKER, J. The first book of information science. Washington, D. C.: U.S. Energy Research and Develop, 1976 apud SARACEVIC, T. Ciência da informação: origem, evolução e relações. Perspectivas em Ciência da Informação, Belo Horizonte, n. 1, v. 1, p. 41-62, jan./jun., 1996.

BELKIN, N. J.; ROBERTSON, S. E. Information science and the phenomenon of information. Journal of the American Society for Information Science, v. 27, n. 4, jul./ago. 1976 apud SARACEVIC, T. Ciência da informação: origem, evolução e relações. Perspectivas em Ciência da Informação, Belo Horizonte, n. 1, v. 1, p. 41-62, jan./jun., 1996.

BLANCHÉ, R. L'épistemologie. Paris: Presses Universitaires de France, 1972.

BORKO, H. Information science: what is it? American Documentation, v.19, n.1, p. 3-5, 1968 apud SARACEVIC, T. Ciência da informação: origem, evolução e relações. Perspectivas em Ciência da Informação, Belo Horizonte, n. 1, v. 1, p. 41-62, jan./jun., 1996.

BUFREM, L. S. Revistas científicas: saberes no campo da ciência da informação. In: POBLACIÓN, D. A.; WITTER, G. P.; SILVA, J. F. M. (Orgs.). Comunicação \& produção científica. São Paulo: Angellara, 2006. p. $193-214$. 
CAMPOS, L. F. B.; VENÂNCIO, L. S. Perspectivas em (in)formação: tendências e tensões entre abordagens físicas, cognitivistas e emergentes. Transinformação, Campinas, v. 19, n. 2, p. 107-118, 2007.

CAPURRO, R. Epistemologia e Ciência da informação. In: ENCONTRO NACIONAL DE PESQUISA EM CIÊNCIA DA INFORMAÇÃO - ENANCIB, 5., 2003, Belo Horizonte. Anais... Belo Horizonte: Escola de Ciência da Informação da UFMG, 2003. [Cd ROM].

CARDOSO, A. M. P. Pós-modernismo e informação: conceitos complementares? Perspectivas em Ciência da Informação, Belo Horizonte, V. 1 , n. 1, p. 63-79, 1996.

FEYERABEND, P. Wilder den Methodenzwang. Frankfurt: Suhkamp, 1979 apud WERSIG, G. Information science: the study of postmodern knowledge usage. Information Processing \& Management, v. 29, n. 2, p. 229-239, 1993.

GOFFMAN, W. Information science: discipline or disappearance. $A S L I B$ Proceedings, v. 22 n.12, p. 589-596, 1970 apud SARACEVIC, T. Ciência da informação: origem, evolução e relações. Perspectivas em Ciência da Informação, Belo Horizonte, n. 1, v. 1, p. 41-62, jan./jun., 1996.

GONZÁLEZ DE GÓMEZ, M. N. Para uma reflexão epistemológica acerca da Ciência da Informação. Perspectivas em Ciência da Informação, Belo Horizonte, v. 6, n. 1, p. 5-18, 2001.

HABERMAS, H. Theorie des kommunikativen Handels. Frankfurt: Suhkamp, 1981 apud WERSIG, G. Information science: the study of postmodern knowledge usage. Information Processing \& Management, $\mathrm{v}$. 29, n. 2, p. 229-239, 1993.

Die neue Unübersichtlichtkeit. Frankfurt: Suhkamp, 1985 apud WERSIG, G. Information science: the study of postmodern knowledge usage. Information Processing \& Management, v. 29, n. 2, p. 229-239, 1993

JAPIASSU, H. Introdução ao pensamento epistemológico. 7. ed. Rio de Janeiro: F. Alves, 1992.

KOCHEN, M. Principies of information retrieval. Los Angeles: Melville, 1974 apud SARACEVIC, T. Ciência da informação: origem, evolução e relações. Perspectivas em Ciência da Informação, Belo Horizonte, n. 1, v. 1, p. 4162, jan./jun., 1996.

KUHN, T. S. A estrutura das revolução científicas. São Paulo: Perspectiva, 2000 apud CAMPOS, L. F. B.; VENÂNCIO, L. S. Perspectivas em (in)formação: tendências e tensões entre abordagens físicas, cognitivistas e emergentes. Transinformação, Campinas, v. 19, n. 2, p. 107-118, 2007.

LALANDE, A. Vocabulário técnico e crítico da filosofia. 3. ed. São Paulo: Martins Fontes, 1999. 
LE COADIC, Y. F. A Ciência da informação. 2. ed. Brasília: Briquet de Lemos/Livros, 2003.

LUHMANN, N. Soziale Systeme. 2. ed. Frankfurt: Suhkamp, 1988 apud WERSIG, G. Information science: the study of postmodern knowledge usage. Information Processing \& Management, v. 29, n. 2, p. 229-239, 1993

MEADOWS, A. J. A comunicação científica. Brasília: Briquet de Lemos, 1999.

SARACEVIC, T. Ciência da informação: origem, evolução e relações. Perspectivas em Ciência da Informação, Belo Horizonte, n. 1, v. 1, p. 4162, jan./jun., 1996.

TENOPIR, C.; KING, D. W. A importância dos periódicos para o trabalho científico. Revista de Biblioteconomia de Brasília, Brasília, v. 25, n. 1, p. 15-26, jan./jun., 2001.

WERSIG, G. Information science: the study of postmodern knowledge usage.

Information Processing \& Management, v. 29, n. 2, p. 229-239, 1993.

\section{Anexo I - Lista dos 91 artigos sobre Epistemologia recuperados da base BRAPCI (15/05/2008)}

1. ALBAGLI, Sarita. Sociedade da informação e do conhecimento: desafios teóricos e empíricos. Liinc em Revista, Florianópolis, v. 3, n. 1, p. 10-16, mar. 2007.

2. ALVARENGA, Lídia. Bibliometria e arqueologia do saber de Michel Foucault: traços de identidade teórico-metodológica. Ciência da Informação, Brasília, v. 27, n. 3, p. 253-261, 1998.

3. ALVARENGA, Lídia. Representação do conhecimento na perspectiva da ciência da informação em tempo e espaço digitais. Encontros Bibli: Revista Eletrônica de Biblioteconomia e Ciência da Informação, Florianópolis, v. 8, n. 15 , p. 18-40, 2003.

4. ANDRADE, Ana Maria Cardoso de; METCHKO, Dulce Maria Bastos; SOLLA, Sheila Ribeiro de Campos. Algumas considerações acerca da situação epistemológica da Biblioteconomia. Revista da Escola de Biblioteconomia da UFMG, Belo Horizonte, v. 10, n. 2, p. 153-162, 1981.

5. ARAÚJO, Carlos Alberto Ávila; ROLIM, Elizabeth Almeida; MARZANO, Isabel Marci Gomes; BITENCOURT, Liara Gomes. A Ciência da Informação na visão dos professores e pesquisadores brasileiros. Informação \& Sociedade: estudos, João Pessoa; v. 17, n. 2, p. 110-127, 2007.

6. ARAÚJO, Eliany Alvarenga de. Por uma ciência formativa e indiciária: proposta epistemológica para a ciência da informação. Encontros Bibli: Revista Eletrônica de Biblioteconomia e Ciência da Informação, Florianópolis, v. 11, n. esp., p. 1-14, 2006. 
7. ARECO, Angela Maria Barreto. Sistemismo x dialética: uma questão de diferenciação de propostas. Transinformação, Campinas, v. 1, n. 2, p. 195-203, 1989.

8. ASSMANN, Hugo. A metamorfose do aprender na sociedade da informação. Ciência da Informação, Brasília, v. 29, n. 2, p. 7-15, 2000.

9. BARRETO, Aldo de Albuquerque. Uma quase historia da ciência da informação. DataGramaZero, Rio de Janeiro, v. 9, n. 2, 2008.

10. BRAGA, Gilda Maria. Informação, ciência, política científica: o pensamento de Derek de Solla Price. Ciência da Informação, Rio de Janeiro, v. 3, n. 2, p. 155-177, 1974.

11. BUFREM, Leilah Santiago. Levantando significações para significantes: da gestão do conhecimento à organização do saber. Encontros Bibli: Revista Eletrônica de Biblioteconomia e Ciência da Informação, Florianópolis, v. 9, n. esp., p. 1-10, 2004.

12. CAMPESTRINI, Danilo; VANDRESEN, Vilmar; PAULINO, Luciana. Interdisciplinaridade: a filosofia como instrumento de diálogo entre as ciências. Revista ACB: Biblioteconomia em Santa Catarina, Florianópolis, v. 5, n. 5,p.145-167,2000.

13. CAMPOS, Astério Tavares. Linguagens documentárias. Revista de Biblioteconomia de Brasília, Brasília, v. 14, n. 1, p. 85-88, jan./jun. 1986.

14. CAMPOS, Luiz Fernando de Barros; VENÂNCIO, Ludmila Salomão. O objeto de estudo da Ciência da Informação: a morte do indivíduo. Informação \& Informação, Londrina, v. 11, n. 1, jan./jun. 2006.

15. CAMPOS, Luiz Fernando de Barros; VENÂNCIO, Ludmila Salomão. Perspectivas em (in)formação: tendências e tensões entre abordagens físicas, cognitivistas e emergentes. Transinformação, Campinas, v. 19, n. 2, p. 107-118, 2007.

16. CAVALCANTI, Cordélia Robalhinho. A interface da pesquisa científica com os sistemas gerais de informação. Revista de Biblioteconomia de Brasília, Brasília, v. 10, n. 1, p. 65-68, jan./jun. 1982.

17. CINTRA, Anna Maria Marques. Subjetividade e interdisciplinaridade na Biblioteconomia. Transinformação, Campinas, v. 8, n. 3, p. 32-43, 1996.

18. CURRÁS, Emília. Informacionismo: teorías neuronales de información. Informação \& Sociedade: Estudos, João Pessoa, v. 14, n. 2, 2004.

19. DERQUI, Pablo Marcos. O paradigma biológico do conhecer e a questão da informação. DataGramaZero, Rio de Janeiro; v. 6, n. 6, 2005.

20. DUMONT, Lígia Maria Moreira; BRUNO, Pedro Paulo Costallat. Ciência da Informação e oportunidade de diálogo intertemático: onde nem tudo é relativo e nem (absolutamente) racional. Perspectivas em Ciência da Informação, Belo Horizonte, v. 8, n. 1, p. 28-39, jan./ jun. 2003. 
21. ESMERALDO, Gema Galgani Silveira Leite. Falando de gênero para informar e formar consciências. Informação \& Sociedade: Estudos, João Pessoa, v. 7, n. 1, p. 68-78, 1997.

22. FERNANDES, Geni Chaves. Fundamentos da informação na abordagem matemática da ciência da informação. Informare: Cadernos do Programa de Pós-Graduação em Ciência da Informação, Rio de Janeiro, v. 5, n. 2, p. 87-97, jul. 1999.

23. FERREIRA, Marcia Xavier. Michel Foucault e a ciência da informação: interações. Informare: Cadernos do Programa de Pós-Graduação em Ciência da Informação, Rio de Janeiro, v. 5, n. 2, p. 38-46, jul. 1999.

24. FIGUEIREDO, Luís Cláudio. Convergências e divergências: a questão das correntes de pensamento em Psicologia. Transinformação, Campinas, v. 4 , n. 1/2/3, p. 15-26, 1992.

25. FRANCELIN, Marivalde Moacir. Abordagens em epistemologia: Bachelard, Morin e a epistemologia da complexidade. Transinformação, Campinas, v. 17, n. 2, p. 101-109, 2005. 26. FRANCELIN, Marivalde Moacir. Ciência, senso comum e revoluções científicas: ressonâncias e paradoxos. Ciência da Informação, Brasília, v. 33, n. 3, p. 26-34, 2004.

27. FRANCELIN, Marivalde Moacir. Configuração epistemológica da Ciência da Informação no Brasil em uma perspectiva pós-moderna: análise de periódicos da área. Ciência da Informação, Brasília, v. 33, n. 2, p. 49-66, 2004.

28. FRANCELIN, Marivalde Moacir. A epistemologia da complexidade e a ciência da informação. Ciência da Informação, Brasília, v. 32, n. 2, p. 6468, 2003.

29. FREIRE, Isa Maria. O olhar da consciência possível sobre o campo científico. Ciência da Informação, Brasília, v. 32, n. 1, p. 50-59, jan. 2003.

30. FREIRE, Isa Maria. A responsabilidade social da Ciência da Informação na perspectiva da consciência possível. DataGramaZero, Rio de Janeiro, v. 5, n. $1,2004$.

31. FREITAS, Lídia Silva de. Entre o público e o privado: trajetos temático-discursivos da área de informação. Informação \& Sociedade: Estudos, João Pessoa, v. 14, n. 1, 2004.

32. GALVÃO, Maria Cristiane Barbosa. Construção de conceitos no campo da ciência da informação. Ciência da Informação, Brasília, v. 27, n. 1, p. 46-52, jan. 1998.

33. GARCÍA GUTIÉRREZ, Antonio. Cientificamente favelados: uma visão crítica do conhecimento a partir da epistemografia. Transinformação, Campinas, v. 18, n. 2, p. 103-112, 2006. 
34. GARCÍA GUTIÉRREZ, Antonio. Connotaciones linguísticas para una teoria de la documentacion. Revista Brasileira de Biblioteconomia e Documentação, São Paulo, v. 21, n. 1/2, p. 9-20, jan/jun. 1988.

35. GARCÍA GUTIÉRREZ, Antonio. Proyectar la memoria: del ordo nacional a la reapropiación crítica. Transinformação, Campinas, v. 15, n. 1, p. 730, jan. 2003.

36. GARCÍA GUTIÉRREZ, Antonio. Teoria de la indización: nuevos parámetros de investigación. Transinformação, Campinas, v. 1, n. 2, p. 147-159, 1989.

37. GASPAROTO, Jayme Wanderley. Ciência e investigação: considerações gerais. Revista Brasileira de Biblioteconomia e Documentação, São Paulo, v. 26, n. 1/2, p. 55-63, jan./jun. 1993.

38. GONZÁLEZ DE GÓMEZ, Maria Nélida. Metodologia da pesquisa no campo da Ciência da Informação. Revista de Biblioteconomia de Brasília, Brasília, v. 23-24, n. 3, p. 333-346, 1999.

39. GONZÁLEZ DE GÓMEZ, Maria Nélida. Metodologia de pesquisa no campo da Ciência da Informação. DataGramaZero, Rio de Janeiro, v. 1, n. $6,2000$.

40. GONZÁlEZ DE GÓMEZ, Maria Nélida. Para uma reflexão epistemológica acerca da Ciência da Informação. Perspectivas em Ciência da Informação, Belo Horizonte, v. 6, n. 1, p. 5-18, jan./jun. 2001.

41. GONZÁLEZ DE GÓMEZ, Maria Nélida. A representação do conhecimento e o conhecimento da representação: algumas questões epistemológicas. Ciência da Informação, Brasília, v. 22, n. 3, p. 217-222, 1993.

42. GONZÁLEZ DE GÓMEZ, Maria Nélida; ORRICO, Evelyn Goyannes Dill. As políticas institucionais das configurações interdisciplinares dos conhecimentos: repercussões nas políticas de informação e nas práticas de avaliação. DataGramaZero, Rio de Janeiro, v. 5, n. 6, 2004.

43. HITOMI, Alberto Haruyoshi. As formas sociais da consciência: 0 pensamento de Antonio Gramsci. Transinformação, Campinas, v. 8, n. 1, p. 31-51, jan. 1996.

44. KOBASHI, Nair Yumiko. Fundamentos semânticos e pragmáticos da construção de instrumentos de representação de informação. DataGramaZero, Rio de Janeiro, v.8, n.6, 2007.

45. LE COADIC, Yves François. Princípios científicos que direcionam a ciência e a tecnologia da informação digital . Transinformação, Campinas, v. 16, n. 3, p. 205-213, 2004.

46. LIMA, Gercina Ângela Borém. Interfaces entre a ciência da informação e a ciência cognitiva. Ciência da Informação, Brasília, v. 32, n. 1, abr. 2003. 
47. LIMA, Marcia H. T. de Figueiredo. Um mundo de discursos raros e memórias frágeis: uma leitura sobre (de)-(in) formações profissionais inspirada em Foucault, Colombo e Pęcheux. Informare: Cadernos do Programa de Pós-Graduaçăo em Ciência da Informação, Rio de Janeiro, v. 5, n. 2, p. 47-56, jul. 1999.

48. LOUREIRO, Maria Lucia de Niemeyer Matheus. Considerações sobre o "espaço do saber" e a sobrevivência do museu a partir de Pierre Lèvy. Informare: Cadernos do Programa de Pós-Graduaçăo em Ciência da Informação, Rio de Janeiro, v. 5, n. 2, p. 78-86, jul. 1999.

49. MARCIANO, João Luiz Pereira. Abordagens epistemológicas e Ciência da Informação: Fenomenologia e Hermenêutica. Transinformação, Campinas, v. 18, n. 3, p. 181-190, 2006.

50. MARCIANO, João Luiz Pereira. Bases teóricas para a formulação de políticas de informação. Informação \& Sociedade: Estudos, João Pessoa, v. 16, n. 2, p. 35-53, jul. 2006.

51. MATHEUS, Renato Fabiano. Rafael Capurro e a filosofia da informação: abordagens, conceitos e metodologias de pesquisa para a Ciência da Informação. Perspectivas em Ciência da Informação, Belo Horizonte, v. 10, n. 2, p. 140-165, jul. 2005.

52. MEDEIROS, Arilene Maria Soares de; MARQUES, Maria Auxiliadora de Resende Braga. Habermas e a teoria do conhecimento. ETD - Educaçăo Temática Digital, Campinas, v. 5, n. 1, p. 1-24, 2003. 53. MIRANDA, Marcos Luiz Calvacanti de. A organização do conhecimento e seus paradigmas científicos: algumas questões epistemológicas. Informare: Cadernos do Programa de Pós-graduaçăo em Ciência da Informação, Rio de Janeiro, v. 5, n. 2, p. 64-77, jul. 1999.

54. MORAES, Alice Ferry de. Os pioneiros da Ciência da Informação nos EUA. Informação \& Sociedade: Estudos, João Pessoa, v. 12, n. 2, p. 101$124,2002$.

55. MORAES, Márcia Oliveira. O conceito de rede na filosofia mestiça. Informare: Cadernos do Programa de Pós-graduaçăo em Ciência da Informação, Rio de Janeiro, v. 6, n. 1, p. 12-20, jan./jun. 2000.

56. MOREIRA, Alexandra; ALVARENGA, Lídia, LIVEIRA, Alcione de Paiva. O nível do conhecimento e os instrumentos de representação: tesauros e ontologias. DataGramaZero, Rio de Janeiro, v. 5, n. 6, 2004.

57. MOREIRO-GONZÁLEZ, José Antonio. Aproximación historica al conocimiento de la comunicación. Transinformação, Campinas, v. 1, n. 3, p. 93-108, 1989.

58. MOREL, Carlos Médicis; MOREL, Regina Lúcia de Moraes. Estudo sobre a produção científica brasileira, segundo os dados do ISI. Ciência da Informação, Rio de Janeiro, v. 7, n. 2, p. 79-83, 1978.

59. MOREL, Carlos Médicis; MOREL, Regina Lúcia de Moraes. Um estudo sobre a produção científica brasileira, segundo os dados do Institute for 
Scientific Information (ISI). Ciência da Informação, Rio de Janeiro, v. 6, n. 2, p. 99-109, 1977.

60. MORO, Eliane Lourdes da Silva; ESTABEL, Lizandra Brasil; SANTAROSA, Lucila Maria Costi; SILVA, Fernando Antonio Abreu e. Projeto Cor@gem: o acesso e o uso das TICs entre pacientes hospitalizados e a interação em ambientes virtuais de aprendizagem. Inclusão Social, Brasília, v. 2, n. 2, p. 130-141, 2007.

61. MOSTAFA, Solange Puntel. Catálogos, dispositivo de interpelação? Perspectivas em Ciência da Informação, Belo Horizonte, v. 8, n. 2, p. 180187, jul. 2003.

62. MOSTAFA, Solange Puntel. A produção de conhecimentos em biblioteconomia. Revista de Biblioteconomia de Brasília, Brasília, v. 11, n. 2, p. 221-229, jul. 1983.

63. MOSTAFA, Solange Puntel; MOREIRA, Walter. Referenciais teóricos da área de informação: sobre Isa e Vânia para os professores da ABEBD. Transinformação, Campinas, v. 11, n. 1, p. 16-26, jan. 1999.

64. MOSTAFA, Solange Puntel; MURGUIA MARAŃON, Eduardo Ismael. Reply to Alvin Schrader on the domains of the Information Science. Transinformação, Campinas, v. 5, n. 1/2/3, p. 31-42, 1993.

65. MOSTAFA, Solange Puntel; MÁXIMO, Luis Fernando. A produção científica da Anped e da Intercom no GT da Educação e Comunicação. Ciência da Informação, Brasília, v. 32, n. 1, p. 96-101, jan. 2003.

66. NEHMY, Rosa Maria Quadros; PAIM, Isis. A desconstrução do conceito de "qualidade da informação". Ciência da Informação, Brasília, v. 27, n. 1, p. 36-45, jan. 1998.

67. NUNES, Claudio Omar Iahnke. A relação da análise documentária com a terminologia. BIBLOS: Revista do Departamento de Biblioteconomia e História, Rio Grande, v. 12, n. 1, p. 99-113, 2000.

68. ODDONE, Nanci. Apontamentos para uma reflexão epistemológica sobre a ciência da informação: Varet, Foucault e Latour. Informare: Cadernos do Programa de Pós-graduaçăo em Ciência da Informação, Rio de Janeiro, v. 5, n. 2, p. 57-63, jul. 1999.

69. ODDONE, Nanci. Revisitando a epistemologia social: esboço de uma ecologia sociotécnica do trabalho intelectual. Ciência da Informação, Brasília, v. 36, n. 1, p. 108-123, jan. 2007.

70. ORTEGA, Cristina Dotta. Relações históricas entre Biblioteconomia, Documentação e Ciência da Informação. DataGramaZero, Rio de Janeiro, v. 5, n. 5, 2004.

71. PINHEIRO, Lena Vania Ribeiro. Processo evolutivo e tendências contemporâneas da Ciência da Informação. Informação \& Sociedade: Estudos, João Pessoa, v. 15, n. 1, 2005. 
72. PINHEIRO, Lena Vania Ribeiro; LOUREIRO, José Mauro Matheus. Traçados e limites da ciência da informação. Ciência da Informação, Brasília, v. 24, n. 1, p. 42-53, jan. 1995.

73. POLKE, Ana Maria Athayde. Relatório dos seminários do Curso de Metodologia do ensino em Biblioteconomia. Revista da Escola de Biblioteconomia da UFMG, Belo Horizonte, v. 7, n. 1, p. 149-200, mar. 1978.

74. POMBO, Olga. Interdisciplinaridade e integração dos saberes. Liinc em Revista, Florianópolis, v. 1, n. 2, p. 4-16, mar. 2005.

75. RENAULT, Leonardo Vasconcelos. Através do espelho: o argumento do "conhecimento do criador" no contexto da cięncia da informaçăo. Encontros Bibli: Revista Eletrônica de Biblioteconomia e Ciência da Informação, Florianópolis, v. 13, n. 24, p. 32-43, 2007.

76. RENAULT, Leonardo Vasconcelos. Paradigmas e modelos: proposta de análise epistemológica para a Ciência da Informação. Informação \& Sociedade: Estudos, João Pessoa, v. 17, n. 2, p. 62-71, 2007.

77. RENAULT, Leonardo Vasconcelos; MARTINS, Ronaldo. O retrato da ciência da informação: uma análise de seus fundamentos sociais. Encontros Bibli: Revista Eletrônica de Biblioteconomia e Ciência da Informação, Florianópolis, v. 12, n. 23, 2007.

78. RENDÓN-RÓJAS, Miguel Angel. Cuestiones Epistemológicas de la ciencia bibliotecológica y de la información. Informare: Cadernos do Programa de Pós-graduaçăo em Ciência da Informação, Rio de Janeiro, v. 5, n. 2, p. 31-37, jul. 1999.

79. RENDÓN-RÓJAS, Miguel Angel. Hacia un nuevo paradigma en Bibliotecologia. Transinformação, Campinas, v. 8, n. 3, p. 17-31, 1996.

80. RENDÓN-RÓJAS, Miguel Angel. Los valores sociales y políticos dentro del paradigma bibliotecológico en la era de la información. Transinformação, Campinas, v. 19, n. 1, p. 9-18, jan. 2007.

81. RIECKEN, Rinalda Francesca. Frame de temas potenciais de pesquisa em Ciência da Informação. Revista Digital de Biblioteconomia \& Ciência da Informação, Campinas, v. 3, n. 2, p. 43-63, jan. 2006.

82. SALES, Rodrigo de. Suportes teóricos para pensar linguagens documentárias . Revista Digital de Biblioteconomia \& Ciência da Informação, Campinas, v. 5, n. 1, p. 95-114, jan./jun. 2007.

83. SANTOS, Plácida Leopoldina Ventura Amorim da Costa; BOTTENTUIT, Aldinar Martins; JORENTE, Maria José V.; GROSSI, Ângela. Infoinclusão digital: uma experiência na cidade de Marília (SP). Revista Brasileira de Biblioteconomia e Documentação: Nova Série, São Paulo, v. 3, n. 2, p. 129-140, jul. 2007. 
84. SHERA, Jesse. Epistemologia social, semântica geral e Biblioteconomia. Ciência da Informação, Rio de Janeiro, v. 6, n. 1, p. 9$12,1977$.

85. SILVA, Marcel Santos; VIDOTTI, Silvana Aparecida Borsetti Gregório. Biblioteca digital geográfica distribuída: uma arquitetura para desenvolvimento. Informação \& Informação, Londrina, v. 12, n. 2, jul. 2007.

86. SILVA, Rubens Ribeiro Gonçalves da. Informação, ciberespaço e consciência. Transinformação, Campinas, v. 18, n. 3, p. 191-201, 2006.

87. SIRIHAL, Adriana Bogliolo; LOURENÇO, Cintia de Azevedo. Informação e conhecimento: aspectos filosóficos e informacionais. Informação \& Sociedade: Estudos, João Pessoa, v. 12, n. 1, p. 67-92, 2002.

88. SOUSA, R. T. B. Classificação de documentos arquivísticos: trajetória de um conceito. Arquivística. Net, Rio de Janeiro, v. 2, n. 2, p. 120-142, 2006.

89. THIESEN, Icléia. Informação, memória e história: a instituição de um sistema de informação na corte do Rio de Janeiro. Encontros Bibli: Revista Eletrônica de Biblioteconomia e Ciência da Informaçăo, Florianópolis, v. 11, n. esp., p. 15-26, 2006.

90. VIEIRA, Jane Eyre G.; MORAIS, Roberto Prado de. A interdisciplinaridade na abordagem das questões ambientais. Comunicação \& Informação, Goiânia, v. 6, n. 2, p. 31-47, jul. 2003.

91. ZANDONADE, Tarcisio. Epistemologia da Ciência da Informação. Revista de Biblioteconomia de Brasília, Brasília, v. 23-24, n. 3, p. 445$448,1999$. 